\title{
Agreement between Observed Rainfall Trends and Climate Change Simulations in the Southwest of Europe
}

\author{
J. F. GonZÁLEZ-Rouco \\ Departamento de Astrofísica y Física de la Atmósfera, Universidad Complutense, Madrid, Spain \\ H. Heyen AND E. ZoRita \\ Institute for Hydrophysics, GKSS Research Centre, Geesthacht, Germany \\ F. VALERO \\ Departamento de Astrofísica y Física de la Atmósfera, Universidad Complutense, Madrid, Spain
}

(Manuscript received 28 October 1998, in final form 26 November 1999)

ABSTRACT

\begin{abstract}
The lowest spatial scale at which current climate models are considered to be skillful is on the order of 1000 $\mathrm{km}$ because of resolution and computer capabilities. The estimation of the regional changes caused by anthropogenic emissions of greenhouse gases and aerosols therefore is problematic. Here a statistical downscaling scheme is used to study the relationship between large-scale sea level pressure and regional precipitation in southwestern Europe, both in observed data and in outputs from a general circulation model (GCM) forced with increasing levels of greenhouse gases and sulfate aerosols. The results indicate that the GCM does reproduce the main aspects of the large- to local-scale coupled variability. Furthermore, these large- to local-scale relationships remain stable in the scenario simulations. The GCM runs predict increases of advection of oceanic air masses to the Iberian Peninsula that will produce a slight decrease of precipitation amounts in the north coast and the opposite effect in the rest of the territory, with values that could reach $10 \mathrm{~mm}$ decade $^{-1}$ in the south. In the homogenized historical records, the obtained pattern of change is very similar. These results support estimations of future regional trends simulated by the GCM under future emission scenarios.
\end{abstract}

\section{Introduction}

Climate change assessment has reached in GCMs the most powerful tool for the evaluation and detection of anthropogenic impacts (IPCC 1996). Although the physical laws that underlie GCMs of the coupled oceanatmosphere system are basically understood, predictions of future climate change are still subject to many uncertainties. It is generally accepted that the current generation of GCMs do not have the required spatial or temporal resolutions for direct assessments of the effects of future changes at the local scale (IPCC 1996). Statistical (Zorita et al. 1992; von Storch et al. 1993; Zorita et al. 1995; Corte-Real et al. 1995; Cui et al. 1995; Heyen et al. 1995) and dynamical (Giorgi et al. 1994; Jones et al. 1995) methods have been developed in the last few years as means of deducing local climate dis-

Corresponding author address: J. F. González-Rouco, GKSS-Forschungszentrum, GUA GEB 38, Max-Planck-Strasse 1, D-21502 Geesthacht, Germany.

E-mail: fidel@gkss.de tributions from the information provided by coarse-resolution GCMs. A review article on these methods, with numerous references therein, was published recently (Wilby and Wigley 1997).

The statistical approaches use empirically obtained relationships between regional climate and the largescale flow to derive subgrid-scale information from GCM gridpoint information in forced scenarios. Once the statistical relationships have been identified in the historical datasets, the predictions of changes in the large-scale as simulated by a GCM can be translated statistically to changes of the local climate. This approach assumes that this relationship will remain stable in the future climate, an assumption based on physical interpretability of the relationship found and in the ability of the statistical model to reconstruct local climate anomalies from the large-scale observations in an independent historical period.

A by-product of this type of analysis is the validation of the GCM from a different point of view, namely, the ability of the GCM to reproduce the relationship between large-scale climate features and local climates. A successful test in this respect can give support to the 
estimations of local climate change based uniquely on the output of GCM greenhouse-gas integrations without the downscaling postprocessing. Related to this question is the stability of the downscaling relationships in an altered climate, which can be assessed only by analyzing high-resolution paleoclimatic data or by comparing similar statistical analysis in a GCM control integration and a simulation with altered greenhouse-gas forcing. Because paleoclimatic data normally are sparse, this second possibility is usually the only feasible one.

This article is focused on testing some of the assumptions underlying the statistical downscaling strategy and to estimate in an application how far the direct output of a sensitivity experiment with a GCM can be from the estimation based on a linear statistical downscaling model supported by a clear physical interpretation. The target regional climate variable throughout the current work is rainfall in the western Mediterranean region in the winter months (December through February), when much of the precipitation occurs. It is known that this variable is controlled to a large extent by the large-scale atmospheric circulation in the North Atlantic and shows at the same time steep spatial gradients caused by orography, which allows for a critical evaluation of the performance of the GCM output and the downscaling model. Rainfall in summertime, on the other hand, generally is caused by convective storms, which are related in a much weaker way to the largescale atmospheric circulation.

\section{Data and statistical downscaling model}

The precipitation dataset consists of 64 stations in the period 1899-1989 and has been subjected previously to a homogenization procedure (Alexandersson 1986; González-Rouco et al. 2000). As a large-scale variable, the sea level pressure (SLP) available from the National Center for Atmospheric Research (NCAR; Trenberth and Paolino 1980) for the North Atlantic region, with a spatial resolution of $5^{\circ} \times 5^{\circ}$, has been used because of the length of time series available.

The statistical procedure is based on canonical correlation analysis (CCA) (Barnett and Preisendorfer 1987; Bretherton et al. 1992). This method isolates linear combinations of multiple predictor variables and linear combinations of multiple predictand variables that have maximum correlation coefficients. The NCAR winter monthly SLP field over the North Atlantic was related to the precipitation in the period 1940-79. Figure 1 shows the resulting three leading pairs of canonical vectors between both signal subspaces. The patterns are ranked according to the canonical correlations, which allow establishment of a direct link between the largescale dynamics and regional rainfall.

The first pair of maps (Fig. 1a, top) matches that in von Storch et al. (1993) and explains most of the rainfall variability $(35 \%)$. It relates (correlation of 0.90 ) negative Atlantic SLP anomalies with positive precipitation anomalies over most of Iberia via moist advection from the west. The negative anomalies in the north coast are likely to be related to the Cantabrian Mountains $(\sim 1500$ $\mathrm{m})$ that act as a natural barrier to the westerly winds.

The analysis also revealed two pairs of dipolelike SLP patterns (Fig. 1a, middle and bottom), so far undetected, whose temporal series show correlations of 0.84 and 0.73 with those of the associated precipitation patterns, the latter explaining $22 \%$ and $17 \%$ of the precipitation variance, respectively. The first of them exhibits negative SLP anomalies over the western Mediterranean Sea that favor onshore advection by northerly winds off the sea to the north of Spain and northwesterly winds to the south. Associated precipitation anomalies show the highest positive values over these areas. In the last canonical pair, negative SLP anomalies in the central North Atlantic drive southwesterly component winds from the Atlantic to the Strait of Gibraltar, favoring the highest values of orographic precipitation in the lands nearby. Also, the southeasterly winds in the north of the peninsula are associated with negative rainfall anomalies.

These results show that most of the variability of winter Iberian rainfall can be explained through moist advection induced by large-scale SLP anomalies. If these downscaling relationships are stable in time, then the good explained variances and correlations would enable one to estimate precipitation variations from the SLP field to a good level of approximation. To confirm this possibility, the obtained canonical vectors and correlations have been used to build a downscaling model $\mathrm{DM}_{\text {obs }}$ that allows hindcasting of the regional precipitation fields using large-scale SLP data as input. We used the same strategy as von Storch et al. (1993) to downscale SLP anomalies from the independent periods 1899-1939 and 1980-89 and compared the estimated $\mathrm{DM}_{\text {obs }}$ precipitation anomalies with the observed ones. The reason to use two widely separated periods is to test that the downscaling model works properly in climates that potentially are as different as the observational record allows. Nevertheless, the results are comparable in both independent periods. Figure 2a shows relatively high values of correlation between observed and modeled rainfall, in the range between 0.5 and 0.9 . Therefore the $\mathrm{DM}_{\mathrm{obs}}$ model may be able to reproduce satisfactorily the winter rainfall in different situations in the past. The rationale of applying the statistical downscaling strategy to a modified climate is the assumption that the statistical model has identified the large-scale configurations that are relevant to regional rainfall and that the climate change signal for rainfall will be given only by changes in the intensity or frequency of these large-scale configurations.

\section{Validation of the GCM}

The GCM used is the Hadley Centre climate model (Johns et al. 1997) with a resolution of $2.5^{\circ}$ latitude $\times$ 
$3.75^{\circ}$ longitude. The outputs of two experiments have been used, starting at model year 1899: 1) a control $\mathrm{CON}$, with constant carbon dioxide $\left(\mathrm{CO}_{2}\right)$ concentrations; 2) an experiment SUL, in which the concentration of $\mathrm{CO}_{2}$ was increased gradually to represent the changes in forcing from all greenhouse gases both in the past and to 2100 under a given scenario and the direct (Mitchell et al. 1995) radiative effect of sulfate aerosols was represented. The concentrations of sulfate aerosols and greenhouse gases after 1990 were based on Intergovernmental Panel on Climate Change (IPCC) scenario IS92a (IPCC 1995), which assumes a slow reduction in the rate of economic growth and a gradual increase in conservation measures. Note that these simulations are meant to represent, for each type of forcing, just one realization of all the possible weather trajectories compatible with the external forcing. Therefore the simulated years cannot be compared directly with the weather actually observed in the real years. In particular, future dates in the control run are purely nominal and are not representative of future climate.

The question of the ability of the GCM to reproduce the observed relationship between the SLP field and Iberian rainfall is addressed first. The spatial windows for the simulated SLP and precipitation were chosen to match those of the observational case, the precipitation field having a comparatively lower resolution than that of the observational data (20 grid points vs 64 stations). December-to-February anomalies from years 2040 to 2079 of CON were used to perform CCA and fit a new statistical model with simulated predictor and predictand variables. The resulting three first pairs of canonical vectors are shown in Fig. $1 \mathrm{~b}$ and, somewhat surprisingly, notably resemble those in Fig. 1a. All three SLP canonical vectors show SLP gradients in the same orientation as the observational patterns. The largest discrepancy appears in the second SLP vector, for which the high pressure cell over the North Atlantic is much weaker in the model data than in the observations. On the other hand, the structure of the three precipitation canonical patterns agrees with the observations, albeit with the limited resolution of the GCM.

A similar study performed with the previous version of the same GCM with lower resolution (Murphy 1994; Noguer 1994) showed that the model was able to reproduce reliably the first CCA vector for SLP and the relative values of the corresponding precipitation pattern at four points over the Iberian Peninsula. Therefore, it is found that the new version of the model does reproduce the three coupled patterns between circulation and rainfall.

These large- to local-scale relationships found in the GCM have been exploited by constructing a new regression model $\left(\mathrm{DM}_{\text {control }}\right)$ such as that for observed data. Figure $2 \mathrm{~b}$ shows correlations between $\mathrm{DM}_{\text {control }}$ estimated using control SLP simulations as inputs to the statistical model and GCM precipitation simulations in the same grid points in a validation period spanning the years 1990-2039 and 2080-2100. A similar pattern with structure similar (though with less local detail) to that of Fig. 2a is obtained.

\section{The downscaling relationship in an altered climate}

Statistical downscaling assumes that the same relations are valid for a future climate, and therefore these relations may be applied to the output of global climate scenario GCM simulations to estimate regional climate changes. This assumption unfortunately will not necessarily hold true. Another widely used hypothesis is that downscaling models will be able to reproduce longterm decadal variability and trends in the perturbed scenarios. This hypothesis is not self evident, because the fitting periods for the statistical model are usually in the range of a few years and the model is based mainly on monthly and yearly variability.

The anomaly integrations from coupled atmosphereocean GCM forced scenarios constitute an ideal framework to test this twofold hypothesis. First CCA has been performed between simulated SLP and simulated rainfall in the last decades of the SUL integration, when the climate change signal should be strongest. The results (not shown) are highly similar to CCA performed in the control run (Fig. 1b). Table 1 shows the correlations between the SLP and precipitation CCA patterns obtained from the CON integration (Fig. 1b) and the SUL integration. Furthermore, within the world of the model simulation, it can be tested whether the $\mathrm{DM}_{\text {control }}$ downscaling model is able to reproduce the climate change signal directly simulated by the GCM at the corresponding model grid points. For this purpose, the trends in the rainfall reconstructed with $\mathrm{DM}_{\text {control }}$ driven by SLP simulated in SUL and the trends obtained directly from the rainfall in SUL have been compared (Figs. 3a,b). Both outputs display positive values in all the territory except for the north coast. Although the downscaled values are more sensitive to the radiative forcing, it becomes evident that the response structures are similar. Both results, the stability of the CCA patterns with respect to greenhouse-gas forcing and the similar trend patterns, support the use of a statistical downscaling model in forced scenarios.

Notice also the close resemblance of the trend structures in Fig. 3 with the correlation patterns of Fig. 2. This resemblence might well be due to the fact that the large-scale anomaly patterns that project these local trends are the same that provide predictability to Iberian rainfall.

An advantage of using a linear downscaling technique is that the behavior of the regional anomaly patterns can be supported by that of the large-scale SLP field. Thus one can trace the history of the regional precipitation response to a certain radiative forcing back to the SLP response to that scenario, adding physical significance to these results. Figure $3 c$ shows the projections of the 
a)
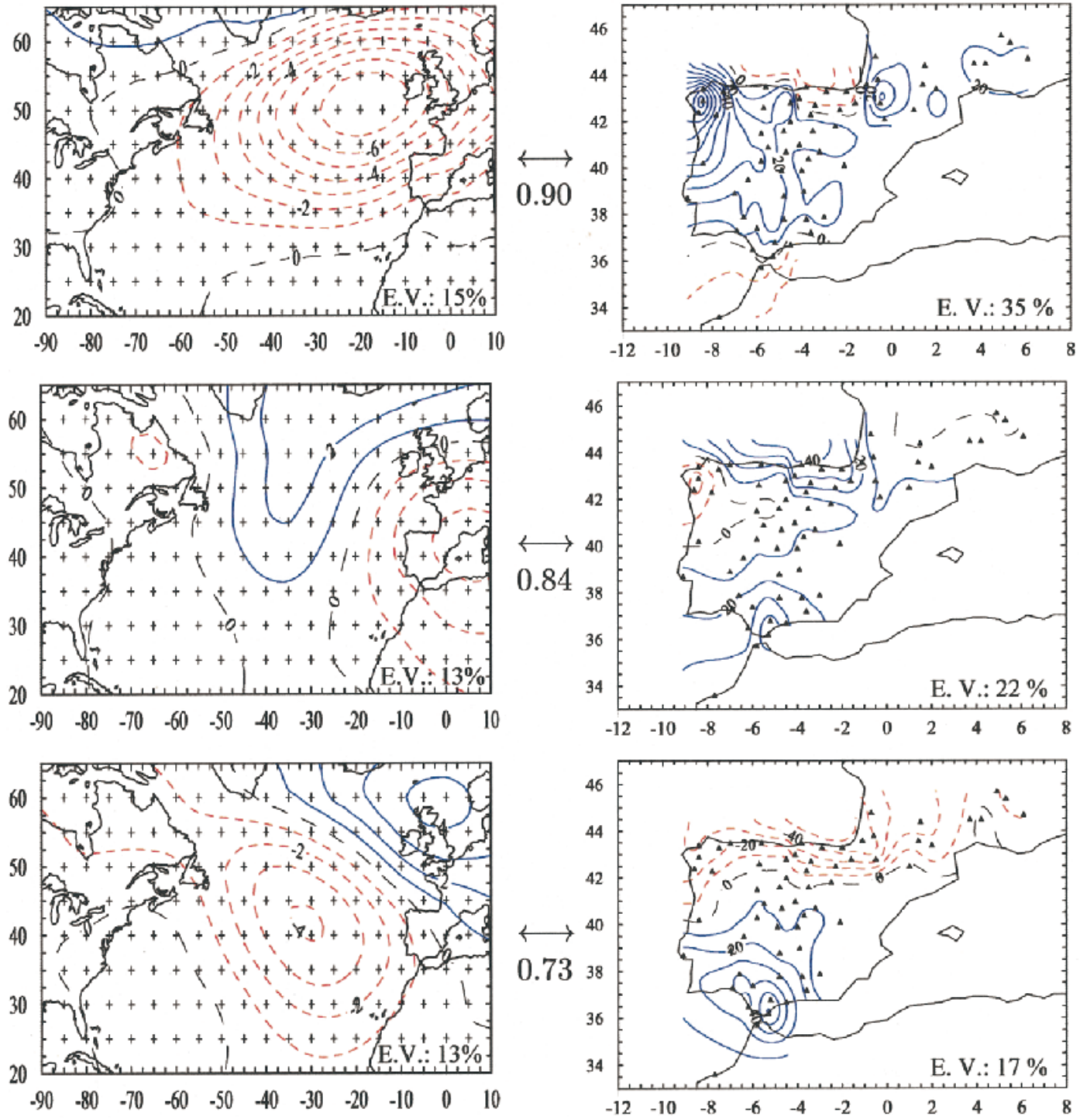

FIG. 1. Three leading pairs of CCA patterns of SLP and Iberian precipitation. Isolines depict typical anomalies (hPa and $\mathrm{mm}$ month $^{-1}$, respectively). Canonical correlations linking the large-scale and the regional-scale patterns are indicated between maps for each pair. As a first step, anomalies from the long-term monthly means were calculated, and the resulting data were detrended. The main signals of both variable fields are extracted previously by means of projecting the original data onto empirical orthogonal functions. Higher-indexed patterns were disregarded because

SUL SLP and precipitation datasets onto the corresponding canonical vectors $\mathrm{DM}_{\text {control }}$. The first and third canonical components show long-term positive trends, and the second one shows a slight downward trend. The response of Iberian precipitation canonical vectors (Fig. $3 c)$ to the evolution of SLP anomalies points out a rise of the first and third component and a slight fall of the second one.

The joint effect of those modes in the model simulation was the one shown in Fig. 3. The use of the $\mathrm{DM}_{\mathrm{obs}}$ will provide a more detailed insight into the spatial distribution of the regional anomalies, however: Figs. 4a and $4 \mathrm{~b}$ show the precipitation linear trends using the SUL SLP and NCAR SLP data as inputs for the DM $\mathrm{Dbs}_{\text {s }}$ model in the period 1900-2100, in comparison with the trends of the observed precipitation data in the period 1930-89 (Fig. 4c). As in previous cases, the outputs have a very similar structure in the three cases. Highlights are negative trends in the north coast and positive trends in the rest of the territory, with values that could 
b)
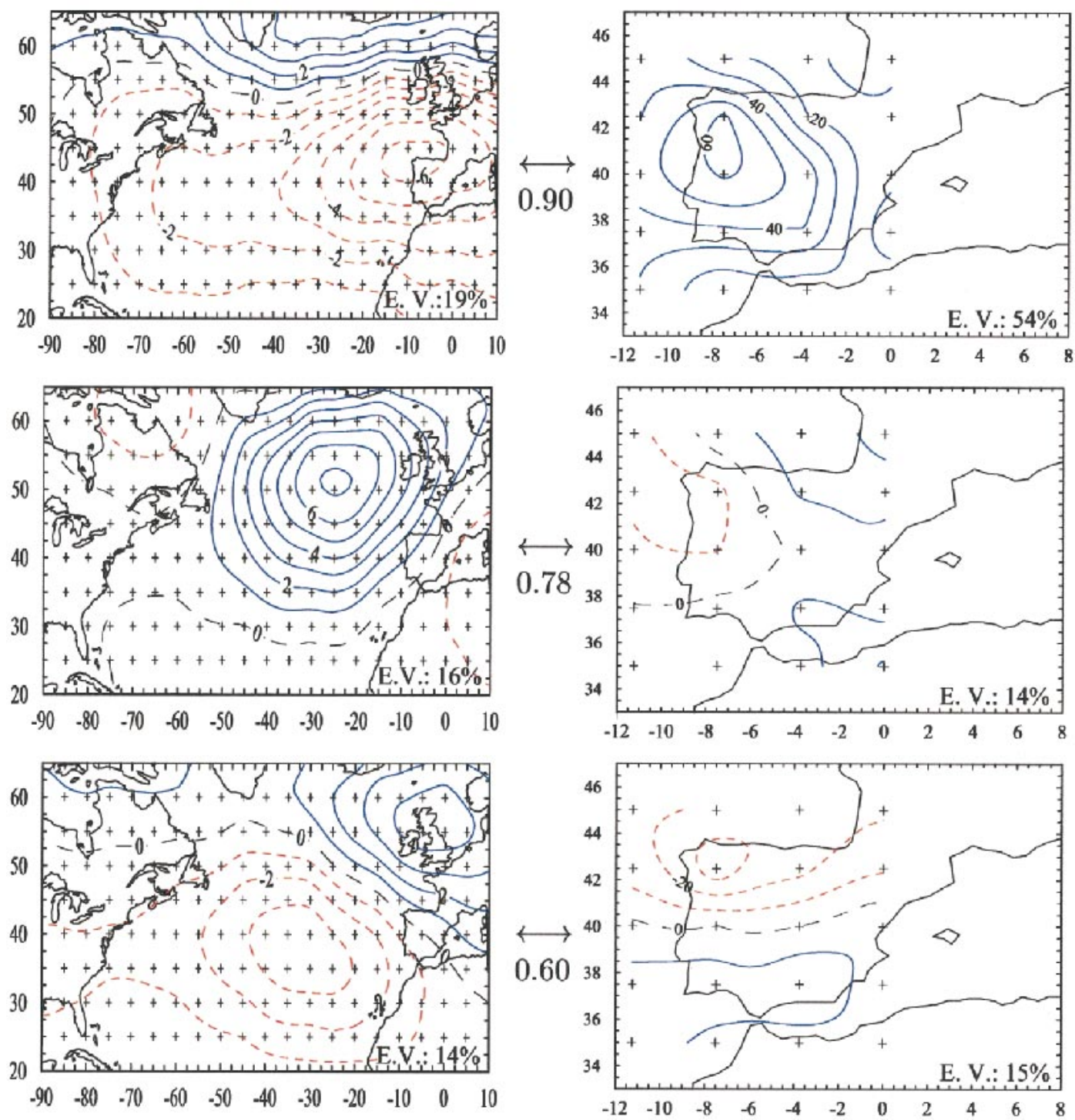

FIG. 1. (Continued) they supplied no additional information that improved the correlation and skill in a validation period. (a) CCA between observed SLP and observed precipitation. (b) CCA between SLP and precipitation simulated in the SUL experiment. The different grid resolution for SLP and precipitation in (b) is due to SLP interpolation onto the same grid resolution as that of the NCAR dataset (a). Explained variance is denoted by E. V.

reach $10 \mathrm{~mm}$ decade $^{-1}$ in the south near the Strait of Gibraltar. This last feature is not evident in the direct GCM simulations of Fig. $3 b$ and is a result of the additional local information contained in $\mathrm{DM}_{\mathrm{obs}}$.

\section{Conclusions}

Some underlying assumptions of statistical downscaling techniques, namely, the stability of the relationships between large-scale climate forcing and the regional climate and the validity of the downscaling relationship to estimate regional climate changes, have been tested in a GCM integration forced by greenhouse-gas and sulfate concentrations according to one IPCC scenario. The downscaling model is based on canonical correlation analysis linking North Atlantic SLP and precipitation in the western Mediterranean in wintertime.

It has been found that the GCM is able to reproduce the three canonical SLP and precipitation patterns identified in the observational datasets to a very high degree of agreement. This result is somewhat surprising, be- 
a)

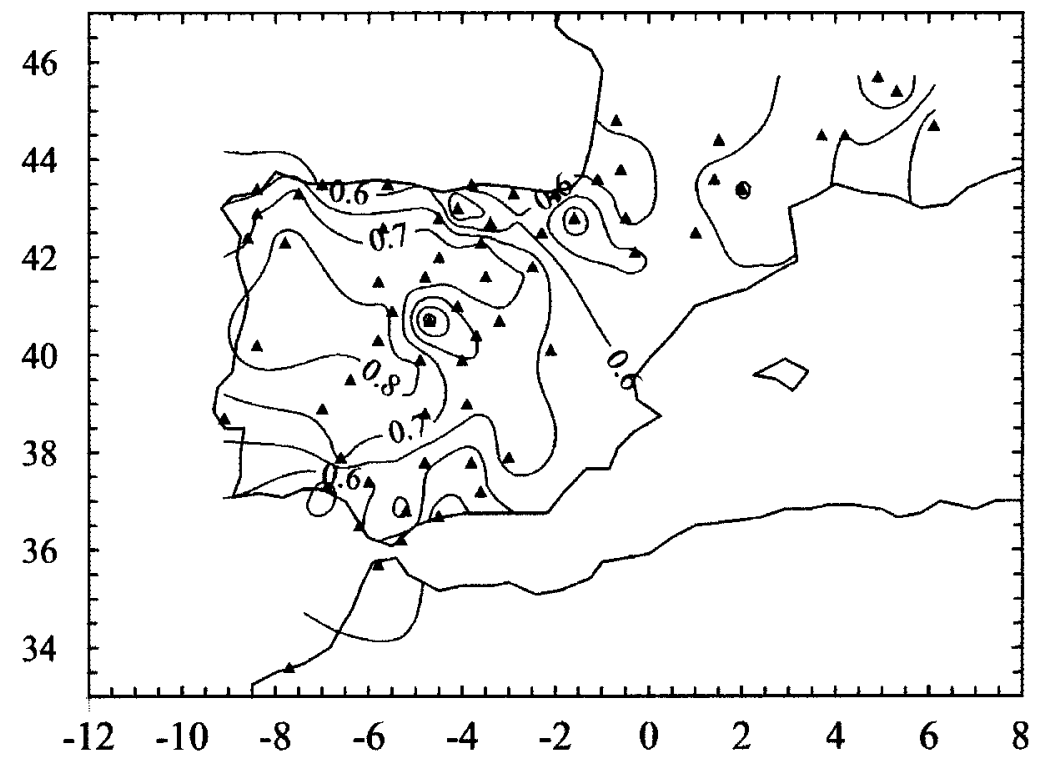

b)

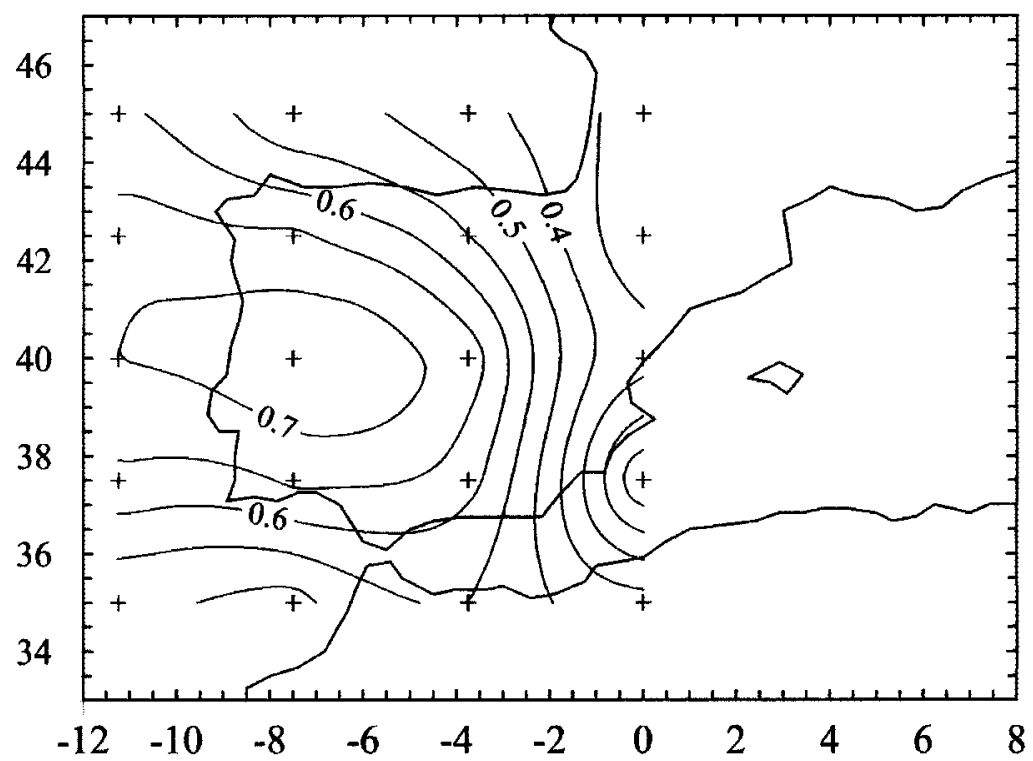

FIG. 2. Spatial distributions of correlations between precipitation values and estimations from the downscaling model in a validation period: (a) 1899-1939/1980-89 NCAR SLP observations as inputs to DM $_{\text {obs }}$ correlated with observed rainfall, (b) 1990-2039/2080-2100 control SLP simulations as inputs to $\mathrm{DM}_{\text {control }}$ correlated to GCM-simulated rainfall. All correlations are above the 99\% significance level.

TABLE 1. Spatial correlations between the three leading SLP and precipitation (PP) CCA patterns obtained from the control and SUL integrations.

\begin{tabular}{lcc}
\hline \hline & SLP & PP \\
\hline CCA1 & 0.89 & 0.98 \\
CCA2 & 0.68 & 0.66 \\
CCA3 & 0.78 & 0.86 \\
\hline
\end{tabular}

cause the resolution of the $\mathrm{GCM}\left(2.5^{\circ}\right.$ lat $\times 3.75^{\circ}$ long $)$ is clearly not the optimal one to capture the complicated orography of this region.

Within the world simulated by the GCM, both downscaling assumptions mentioned above were fulfilled: the canonical patterns calculated in the control run are practically the same in the last decades of integration; also, the $\mathrm{DM}_{\text {control }}$ downscaling model derived from the CCA in the control run forced with the simulated SLP in the SUL experiment is able to reproduce the simulated rain- 
a)

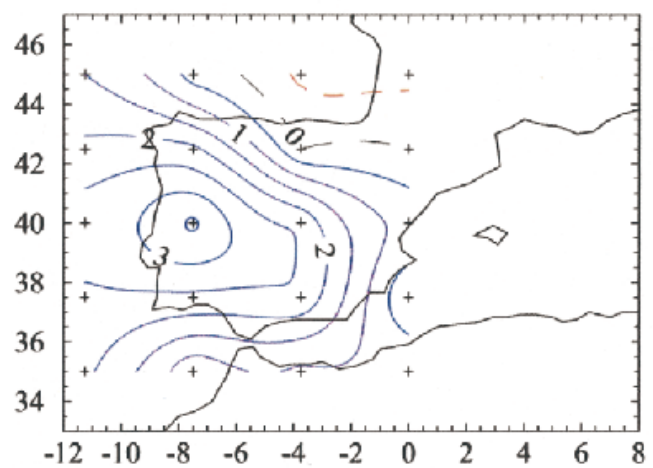

b)

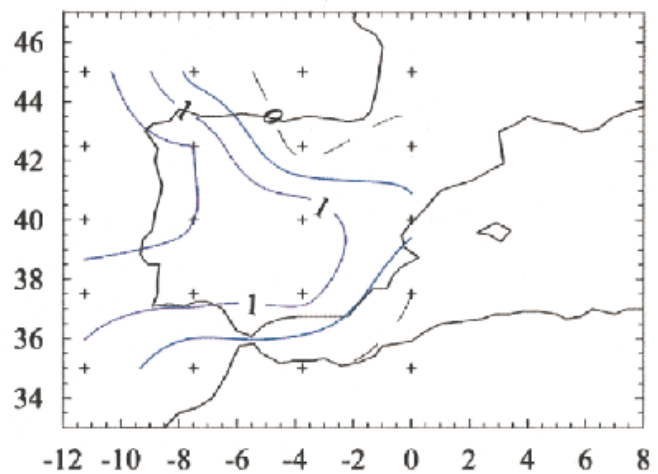

c)

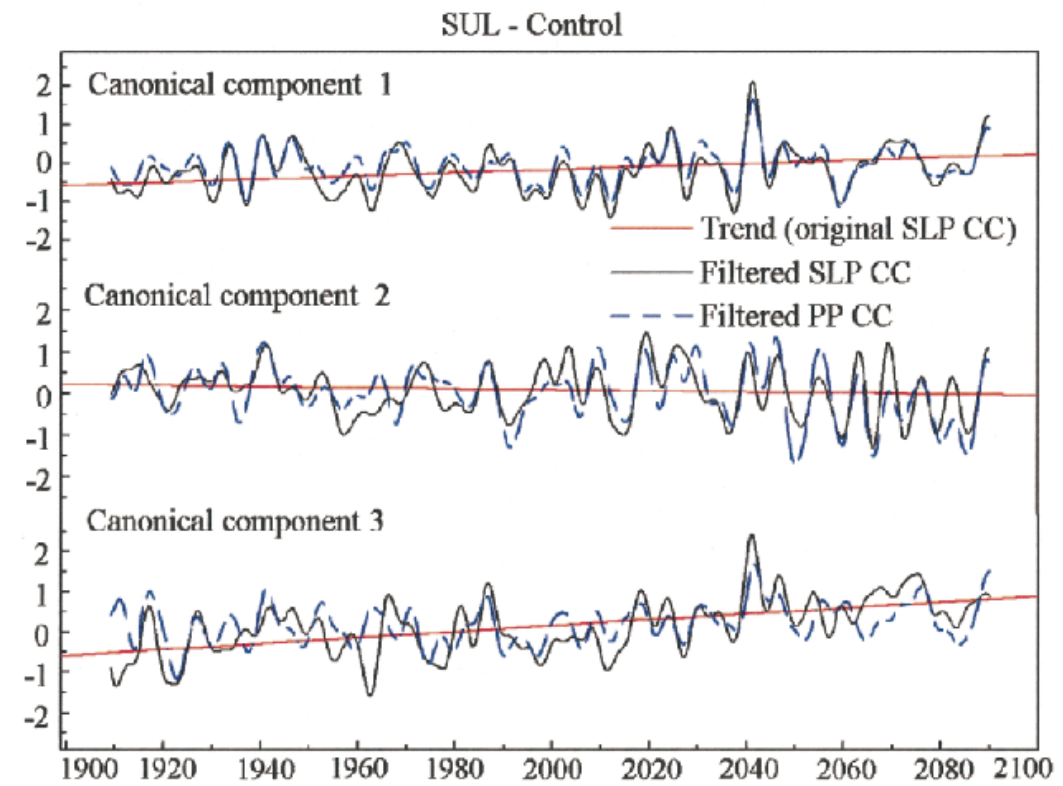

FIG. 3. Spatial distribution of precipitation trends $\left(\mathrm{mm}\right.$ month $^{-1}$ decade $\left.^{-1}\right)$ from the SUL experiment: (a) downscaled from simulated large-scale SLP and (b) direct GCM integrations; (c) projections of the SUL SLP (black) and precipitation (blue) integrations over the three canonical vectors, filtered through a 3-yr low-pass filter. Anomalies were calculated from the control integration means for the period 2040-79. Linear trends for the nonfiltered SLP data are plotted in red.

fall at the GCM grid points in the same experiment. This success indicates that $\mathrm{DM}_{\text {control }}$ captures the most part of the relevant large-scale forcing of precipitation, and the climate change in the model is reflected mostly in changes of the intensity or the frequency of the forcing patterns and not in changes of the downscaling relationship itself. A source of uncertainty, however, must remain, namely, whether the simulated changes of the intensity of the large-scale forcing (Fig. 3c) will correspond to reality.
The combination of SUL GCM output and DM $\mathrm{Dbs}_{\mathrm{ob}}$ provides a picture of the extended trends in regional precipitation in the SUL scenario, namely, decreases of precipitation in the north coast and increases to the south. These changes are related to increases of the intensity of the first and third SLP CCA patterns and a decrease of the second one, that is, increase of oceanic flow from the west and southwest and decrease of northwestern flow to the Bay of Biscay.

It perhaps is noteworthy that the spatial structure of 
a)

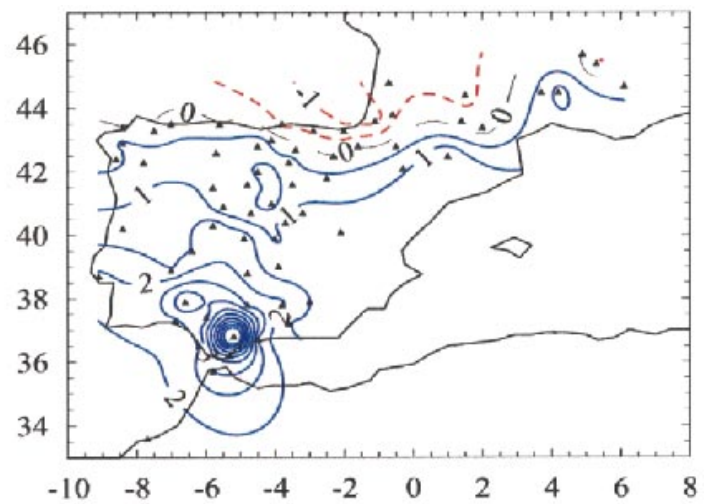

b)

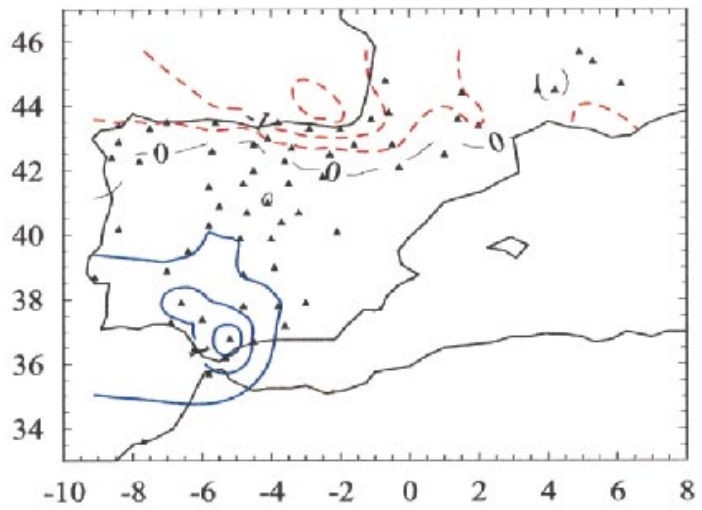

c)

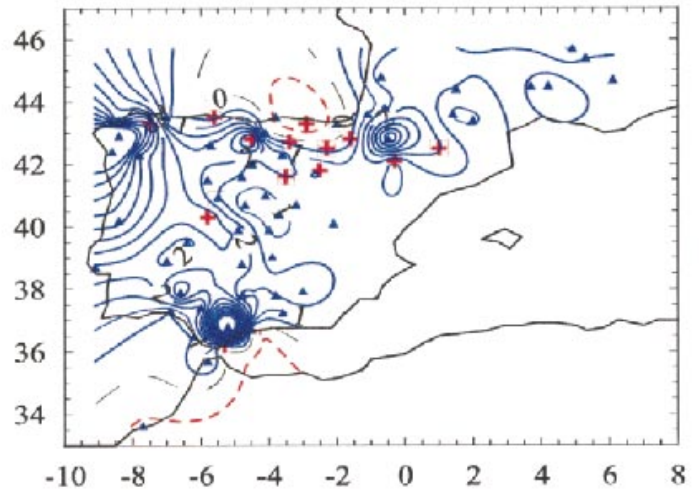

FIG. 4. Spatial distribution of precipitation trends $\left(\mathrm{mm}\right.$ month $^{-1}$ decade $^{-1}$ ) of (a) NCAR SLP anomalies downscaled by $\mathrm{DM}_{\text {obs }}$, (b) SUL SLP anomalies downscaled by $\mathrm{DM}_{\mathrm{obs}}$, and (c) observed precipitation for the period 1930-89. Observed precipitation data in (c) were previously treated with a homogenization procedure (Alexandersson 1986; Hanssen-Bauer and Forland 1994); before trends were calculated, data were projected onto the precipitation canonical vectors. Symbols in (c) stand for the sign of the trends in raw data after 1930: triangles represent positive trends, and crosses represent negative trends (squares and circles stand for negative values when the time interval under consideration begins in 1910 and 1920, respectively).

the future trends in rainfall downscaling with $\mathrm{DM}_{\mathrm{obs}}$ from the SLP scenario simulation also fit reasonably well with the observed rainfall linear trends since 1930. A climate change detection strategy (Hegerl et al. 1996) with only this regional variable perhaps is not reasonable, however, and has not been attempted.

Acknowledgments. The authors thank the Hadley Centre for supplying the model data and two anonymous referees for their helpful comments. Funding was provided by the Comunidad de Madrid, Project CLI970341-c0301, and the Ramón Areces Foundation.

\section{REFERENCES}

Alexandersson, H., 1986: Homogeneity test applied to precipitation data. J. Climatol., 6, 661-675.

Barnett, T. P., and R. W. Preisendorfer, 1987: Origins and levels of monthly and seasonal forecast skill for United States surface air temperatures determined by canonical correlation analysis. Mon. Wea. Rev., 115, 1825-1850.

Bretherton, C. S., C. Smith, and J. M. Wallace, 1992: An intercomparison of methods to find coupled patterns in climate data. $J$. Climate, 5, 541-560.

Corte-Real, J., X. Zhang, and X. Wang, 1995: Downscaling GCM information to regional scales: A non-parametric multivariate regression approach. Climate Dyn., 11, 413-424.

Cui, M., H. von Storch, and E. Zorita, 1995: Coastal sea level and the large-scale climate state: A downscaling exercise for the Japanese Islands. Tellus, 47A, 132-144.

Giorgi, F., C. Shields Brodeur, and G. T. Bates, 1994: Regional climate change scenarios over the United States produced with a nested regional climate model. J. Climate, 7, 375-399.

González-Rouco, J. F., J. L. Jimenez, V. Quesada, and F. Valero, 2000: Quality control and homogeneity of precipitation data in the southwest of Europe. J. Climate, in press.

Hanssen-Bauer, I., and E. J. Forland, 1994: Homogenizing long Norwegian precipitation series. J. Climate, 7, 1001-1013.

Hegerl, G. C., H. von Storch, K. Hasselmann, B. D. Santer, U. Cubasch, and P. D. Jones, 1996: Detecting greenhouse-gas-induced climate change with an optimal fingerprint method. J. Climate, 9, 2281-2306.

Heyen, H., E. Zorita, and H. von Storch, 1996: Statistical downscaling of monthly mean North Atlantic air-pressure to sea level anomalies in the Baltic Sea. Tellus, 48A, 312-323.

IPCC, 1995: Climate Change 1994-Radiative Forcing of Climate Change and an Evaluation of the IPCC IS92 Emission Scenarios. J. T. Houghton et al., Eds, Cambridge University Press, $198 \mathrm{pp}$.

—, 1996: Climate Change 1995-The Science of Climate Change. J. T. Houghton et al., Eds., Cambridge University Press, 584 pp.

Johns, T. C., R. E. Carnell, J. F. Crossley, J. M. Gregory, J. F. B. Mitchell, C. A. Senior, S. F. B. Tett, and R. A. Wood, 1997: The second Hadley Centre coupled ocean-atmosphere GCM: Model description, spin-up and validation. Climate Dyn., 13, 103-134.

Jones, R. G., J. M. Murphy, and M. Noguer, 1995: Simulation of climate change over Europe using a nested regional-climate model. I: Assessment of control climate, including sensitivity to location of lateral boundaries. Quart. J. Roy. Meteor. Soc., 121, 1413-1449.

Mitchell, J. F. B., T. C. Johns, J. M. Gregory, and S. F. B. Tett, 1994: Climate response to increasing levels of greenhouse gases and sulphate aerosols. Nature, 376, 501-504.

Murphy, J. M., 1995: Transient response of the Hadley Centre coupled ocean-atmosphere model to increasing carbon dioxide. Part I: Control climate and flux adjustment. J. Climate, 8, 36-56.

Noguer, M., 1994: Using statistical techniques to deduce local climate distributions: An application for model validation. Meteor. Appl., 1, 227-287.

Trenberth, K. E., and D. A. Paolino Jr., 1980: The Northern Hemi- 
sphere sea level pressure dataset: Trends, errors and discontinuities. Mon. Wea. Rev., 108, 856-872.

von Storch, H., E. Zorita, and U. Cubasch, 1993: Downscaling of global climate estimates to regional scales: An application to the Iberian rainfall in wintertime. J. Climate, 6, 1161-1171.

Wilby, R. L., and T. M. L. Wigley, 1997: Downscaling general circulation model output: A review of methods and limitations. Prog. Phys. Geogr., 21, 530-548.
Zorita, E., E. Kharin, and H. von Storch, 1992: The atmospheric circulation and the sea surface temperature in the North Atlantic area in winter: Their interaction and relevance for Iberian precipitation. J. Climate, 5, 1097-1108.

, J. P. Hughes, D. P. Lettenmaier, and H. von Storch, 1995: Stochastic characterization of regional circulation patterns for climate model diagnosis and estimation of local precipitation. $J$. Climate, 8, 1023-1042. 